\title{
Real-Time Two-Dimensional Imaging of Potassium Ion Distribution Using an Ion Semiconductor Sensor with Charged Coupled Device Technology
}

\author{
Toshiaki Hattori, ${ }^{* 1, * 2 \dagger}$ Yoshitomo MaSaKI, ${ }^{* 3}$ Kazuya Atsumi, ${ }^{* 4}$ Ryo Kato, ${ }^{* 5}$ and \\ Kazuaki SAWADA $* 1, * 2$ \\ *1 Department of Electrical and Electronic Information Engineering, Toyohashi University of Technology, \\ 1-1 Hibarigaoka, Tempaku, Toyohashi 441-8580, Japan \\ *2 JST CREST, Chiyoda, Tokyo 102-0075, Japan \\ *3 Department of Materials Science, Toyohashi University of Technology, 1-1 Hibarigaoka, Tempaku, \\ Toyohashi 441-8580, Japan \\ *4 Department of Electrical and Electronic Engineering, Toyohashi University of Technology, 1-1 Hibarigaoka, \\ Tempaku, Toyohashi 441-8580, Japan \\ *5 Cooperative Research Facility Center, Toyohashi University of Technology, 1-1 Hibarigaoka, Tempaku, \\ Toyohashi 441-8580, Japan
}

\begin{abstract}
Two-dimensional real-time observation of potassium ion distributions was achieved using an ion imaging device based on charge-coupled device (CCD) and metal-oxide semiconductor technologies, and an ion selective membrane. The CCD potassium ion image sensor was equipped with an array of $32 \times 32$ pixels (1024 pixels). It could record five frames per second with an area of $4.16 \times 4.16 \mathrm{~mm}^{2}$. Potassium ion images were produced instantly. The leaching of potassium ion from a $3.3 \mathrm{M} \mathrm{KCl} \mathrm{Ag} / \mathrm{AgCl}$ reference electrode was dynamically monitored in aqueous solution. The potassium ion selective membrane on the semiconductor consisted of plasticized poly(vinyl chloride) (PVC) with bis(benzo-15-crown-5). The addition of a polyhedral oligomeric silsesquioxane to the plasticized PVC membrane greatly improved adhesion of the membrane onto $\mathrm{Si}_{3} \mathrm{~N}_{4}$ of the semiconductor surface, and the potential response was stabilized. The potential response was linear from $10^{-2}$ to $10^{-5} \mathrm{M}$ logarithmic concentration of potassium ion. The selectivity coefficients were $K_{\mathrm{K}^{*}, \mathrm{Li}^{+}}^{\mathrm{pot}}=10^{-2.85}$, $K_{\mathrm{K}^{+}, \mathrm{Na}^{+}}^{\mathrm{pot}}=10^{-2.30}, K_{\mathrm{K}^{+}, \mathrm{Rb}}^{\mathrm{pot}}=10^{-1.16}$, and $K_{\mathrm{K}^{+}, \mathrm{Cs}^{+}}^{\mathrm{pot}}=10^{-2.05}$.
\end{abstract}

(Received July 21, 2010; Accepted August 18, 2010; Published October 10, 2010)

\section{Introduction}

Chemical microscopes can be used to obtain clear images that display localized chemical and biochemical materials. Various types of chemical microscopes with micrometer-scale resolution have been applied to biological systems. ${ }^{1}$ Evolution of the microscope has yielded techniques such as light-addressable potentiometric sensor (LAPS), ${ }^{2}$ which belongs to a contact-type sensor and which is label-free (maker-free) and non-invasive, in contrast with a fluorescence microscope. LAPS is an ion sensor of metal-oxide semiconductor (MOS). MOS technology allows miniaturization of devices, has low power consumption, can be batch fabricated to industrial standards, and is economical However, LAPS operates by the scanning light pulse technique, and it is difficult to fabricate the light scanning systems in MOS circuit processes. Technical improvements of LAPS in portability, robustness, and handling have been taking place. ${ }^{3}$ An alternative MOS technology for development of an easy to handle chemical microscope is a two-dimensional sensor with

$\dagger$ To whom correspondence should be addressed.

E-mail: thattori@ee.tut.ac.jp many regularly arranged sensing pixels. Some array devices such as the ion sensor field-effective transistor (ISFET), fabricated in MOS circuit process, have been developed. ${ }^{4}$

Another new type of ion sensor fabricated by complimentary MOS (CMOS) processes that incorporated a $\mathrm{pH}$ sensor using charge-coupled device (CCD) technology had been developed by Sawada et al. ${ }^{5}$ The chemical sensing area for the hydrogen ion included a layered $\mathrm{Si}_{3} \mathrm{~N}_{4}$ film $\left(\mathrm{Si}_{3} \mathrm{~N}_{4} / \mathrm{SiO}_{2} / \mathrm{p}\right.$-type $\mathrm{Si}$ (p-Si) substrate) similar to an ISFET. However, the signal treatment of chemical potential change was different from that of a typical ISFET. A chemical potential on the $\mathrm{Si}_{3} \mathrm{~N}_{4}$ surface produced a potential well in the $\mathrm{p}$-Si substrate. The depth of the potential well corresponded to the $\mathrm{pH}$ of the solution. Thereby, at first, the potential well was filled with electric charges from an input charge source. According to the CCD technique, these electric charges transferred to a floating diffusion, and the potential of the floating diffusion was measured. Consequently, a CCD ion sensor transforms change in $\mathrm{pH}$ to a quantity of electric charges, while an ISFET transforms change in $\mathrm{pH}$ to a shift in the drain current or voltage.

CCD ion sensors provide a convenient method to fabricate two-dimensional chemical image sensors based on CMOS. Two-dimensional CCD $\mathrm{pH}$ sensors equipped with 100 pixels 
$(10 \times 10)^{6}$ and 1024 pixels $(32 \times 32)^{7}$ have been developed for $\mathrm{pH}$ sensing. Images of the $\mathrm{pH}$ of a biological sample were successfully obtained using a 200-ms step, while the recording time of a LAPS microscope was not as rapid. ${ }^{8}$ The two-dimensional CCD image sensor technique is convenient because it is simple, compact, and rapid. This technique has also been applied to DNA sensing. ${ }^{9}$

In this paper, we reported the first development of a CCD ion imaging sensor using a plasticized poly(vinyl chloride) (PVC) membrane. Plasticized PVC membrane is easy to prepare, and a range of its ion selective membranes can be prepared for metal ions, inorganic anions, organic ions, and polyelectrolytes. Among them, we developed a potassium ion image sensor. Potassium ion is important for medical science, biology, and food science. There are many reports of the use of plasticized PVC membrane as potassium ion selective electrode (ISE). ${ }^{10-24}$ The plasticized PVC membrane was prepared from a typical mixture of neutral-carrier-type ionophore, ion-exchanging material, and plasticizer. During development of the CCD potassium ion sensor, however, poor adhesion of plasticized PVC membranes to the device surface was an obstacle. We found that the addition of a polyhedral oligomeric silsesquioxane (POSS) into the plasticized PVC membrane improved adhesion and caused stability of the sensor response. The developed sensor was successfully used to visualize the leaching of potassium ion from a $3.3 \mathrm{M} \mathrm{KCl} \mathrm{Ag/AgCl}$ reference electrode.

\section{Experimental}

\section{Reagents and solutions}

Bis[(benzo-15-crown-5)-4-methyl]pimelate (bis(benzo-15crown-5)), potassium tetrakis (4-chlorophenyl)borate (K-TCPB), and 2-nitrophenyl octyl ether (NPOE) were purchased from Dojindo Laboratories (Japan). The POSS 1,3,5,7,9,11,13,15octa(propylmethacryl)pentacyclo-[9.5.1.1 $\left.3,9 \cdot 1^{5,15} \cdot 1^{7,13}\right]$ octasiloxane (OPMPCOS), high molecular weight PVC (average $M_{\mathrm{W}}=$ 500000), and tris(hydroxymethyl)aminomethane (Tris) were purchased from Sigma-Aldrich. Dioctyl phthalate (DOP) and other reagents were prepared from analytical reagent grade chemicals (Wako Pure Chemicals, Japan). Water used in the experiments was prepared with a Milli-Q system. Metal ion solutions for the experiments were prepared daily by dilution from a $1 \mathrm{M}$ stock solution of the metal chlorides.

\section{Principle and operation}

A schema for the measurement principle and its operation ${ }^{6}$ on the developed CCD sensor is shown in Fig. 1. The construction corresponding to the electrochemical cell was as follows; the reference $\mathrm{Ag} / \mathrm{AgCl}$ electrode/sample solution/PVC membrane/the semiconductor sensor $\left(\mathrm{Si}_{3} \mathrm{~N}_{4} /\right.$ thin $\left.\mathrm{SiO}_{2} / \mathrm{p}-\mathrm{Si}\right)$. The concentration of analyte ion in the sample solution influenced the potential of the PVC membrane. The potential change altered the depth of the potential well formed in the surface of the $\mathrm{p}$-Si under the thin $\mathrm{SiO}_{2}$ layer. The potential well depth was measured as the amount of charge accumulated in the sensor using the CCD technique.

To conduct the CCD technique, we developed a CMOS device that consisted of seven parts: an input diode (ID), an input control gate (ICG), a sensing region of $\mathrm{p}$-Si, a transfer gate (TG), a floating diffusion (FD), a reset switch (RES), and a source follower circuit. Each operation was controlled by a pulse generator and a personal computer. The output signal was processed through an external analog-digital converter and recorded by the computer. At first, the RES opened and the

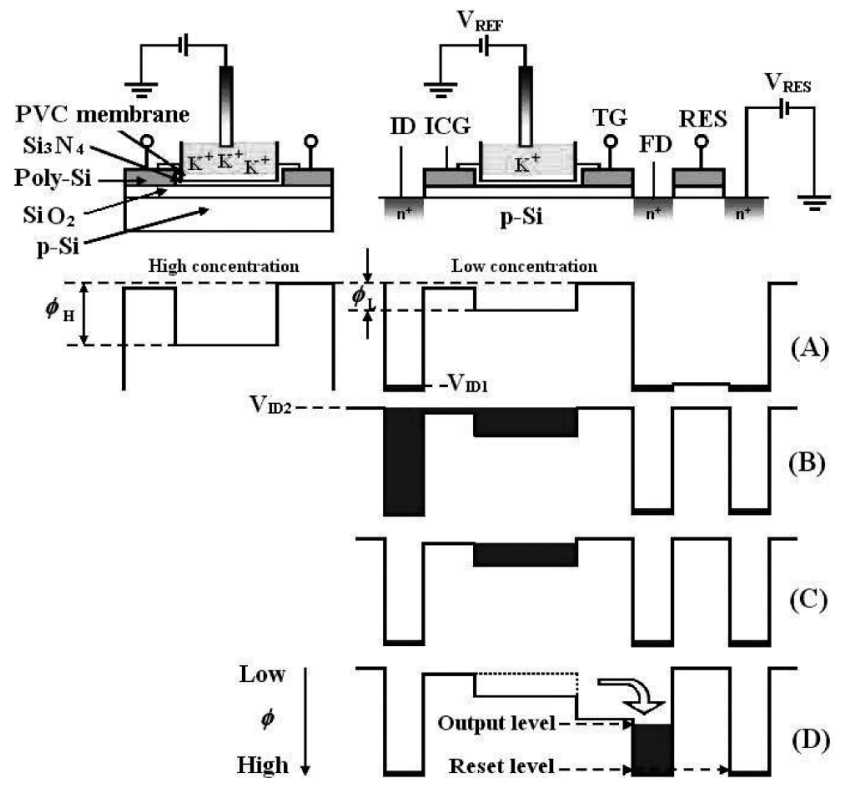

Fig. 1 Schematic representation of the CCD ion sensor including an input diode (ID), an input control gate (ICG), a p-Si sensing region, a transfer gate (TG), a floating diffusion (FD), a reset switch (RES), and a source follower circuit. The sequence included: (A) initiation and reset of pixel, (B) charge injection from ID to a potential well under sensing area, (C) end of charge injection, and (D) charge transfer to a FD.

potential of FD and the clock cycle was initiated (Fig. 1(A)). The potential of the ID decreased from a reset potential (VID1) to a lower limit potential (VID2) and electric charge flowed into the potential well of p-Si (Fig. 1(B)). The potential of the ID reversed from VID2 to VID1, and a packet of electric charge formed that corresponded to the depth of the potential well stored in the p-Si layer (Fig. 1(C)). The TG opened and the packet of electric charge transferred to a FD (Fig. 1(D)). The potential of the FD was read using the source follower circuit.

\section{Instrumentation and measurement of ion image sensor}

The measurement system, including sensor, pulse generator, and computer, has been described previously. ${ }^{6}$ The image sensor of 1024 pixels $(32 \times 32$ pixels $)$ fabricated in a CCD/CMOS circuit process is shown in Fig. 2. The area of the image sensor was $4.16 \times 4.16 \mathrm{~mm}^{2}$ (Fig. 2(A)). Each pixel was $130 \mu \mathrm{m}$ square, and the sensing region was about $40 \mu \mathrm{m}$ square (Fig. 2(B)). Each pixel had a selection transistor, which could turn on the select signal. The select signal for each pixel was supplied externally from a pulse generator. The signals were output serially after being converted into electrical voltage signals in each pixel. The output signals from the sensors were processed through an external analog-to-digital converter before being input to a computer. The time interval for one pixel from the first reset to the readout was $333 \mu \mathrm{s}$. Computer software converted the signals into real-time moving images at five frames per second. The ion images were measured in a dark box to avoid the influence of electric charge produced from the photo-sensitivity of p-Si.

Since the CCD ion sensor measures the amount of charges in the surface of the p-Si layer under the thin $\mathrm{SiO}_{2}$ layer, the output signal is a potential translated by the source follower circuit from the floating diffusion. Therefore, the output potential is not consistent with the membrane potential. The observed 


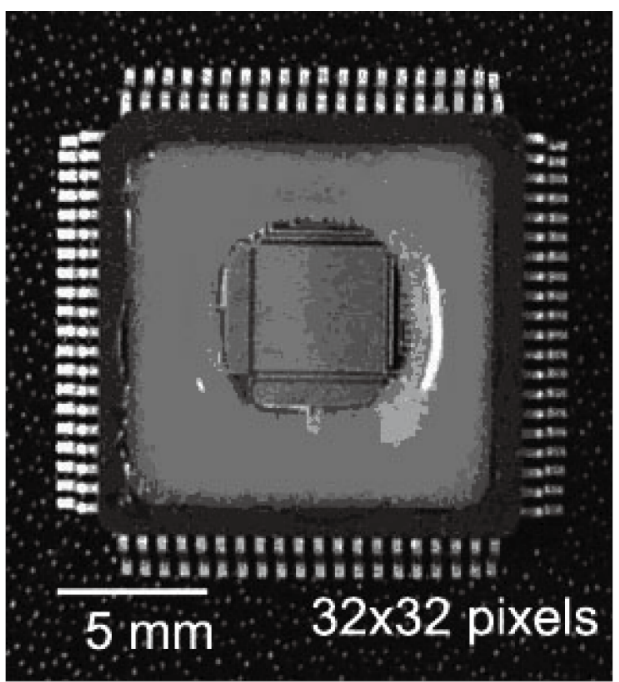

(A)

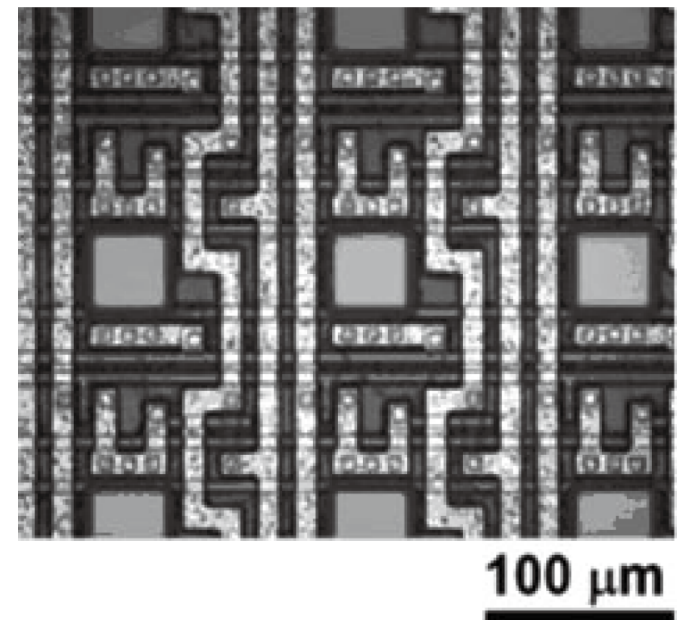

(B)

Fig. 2 Photographs of the CCD ion image sensor: (A) $32 \times 32$ pixel $\mathrm{pH}$ image sensor tip, and (B) close up photograph of the pixels.

potential is due to the capacities of the sensing area and FD in one pixel, and a transfer gain of the source follower circuit. The ideal out-put value was $31.5 \mathrm{mV}$ decade $^{-1}$, which was determined from multiplying the total out-put gain by the Nernstian slope. The total out-put gain was obtained by multiplying a transfer gain by a source follower gain. The transfer gain was a ratio of the electric capacity of $\mathrm{p}$-Si to the electric capacity of FD. The mean value for a CCD ion image sensor with $\mathrm{Si}_{3} \mathrm{~N}_{4}$ surface was $27.2 \mathrm{mV} \mathrm{pH}^{-1}$, which was obtained from measurement of buffer solutions at three $\mathrm{pH}$ values: $\mathrm{pH} 4, \mathrm{pH} 7$, and $\mathrm{pH} 9$.

\section{Plasticized PVC membrane}

A mixture for production of the optimum plasticized membrane was prepared by dissolving the following components in $5.0 \mathrm{~mL}$ of tetrahydrofuran: $2.6 \mathrm{mg}$ of bis(benzo-15-crown-5), $1.3 \mathrm{mg}$ of K-TCPB, $22 \mathrm{mg}$ of DOP, $30 \mathrm{mg}$ of POSS, and $44 \mathrm{mg}$ of PVC. The membrane mixture $(25 \mu \mathrm{L})$ was poured onto the surface of the sensor (about $7 \mathrm{~mm}$ square) by drop-casting. The film was left to dry for least $12 \mathrm{~h}$ at room temperature. The membrane thickness was measured by a laser microscope (VK-8510, Keyence Co. Ltd., Japan). The membrane was transparent to the laser light, then, part of the membrane on the

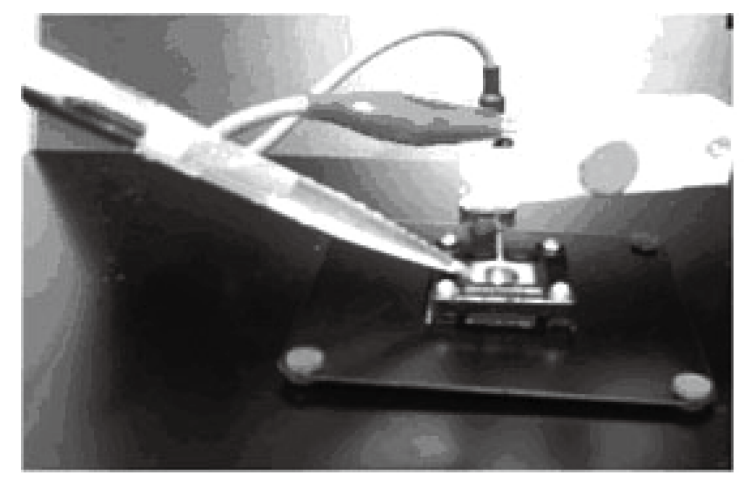

Ag/AgCl electrode

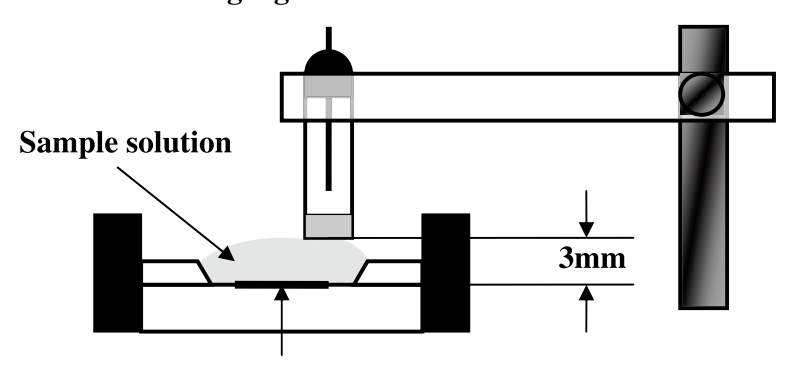

CCD ion image sensor

Fig. 3 Arrangement of CCD ion image sensor and a reference electrode during sample solution measurement.

semiconductor was stripped away, and carbon was deposited on the stripped surface by a carbon coater. The membrane thickness was $1.5 \pm 0.3 \mu \mathrm{m}$.

\section{Measurement of potassium ion concentrations}

The sensor was conditioned with $10^{-3} \mathrm{M}$ potassium chloride solution for more than $6 \mathrm{~h}$. All measurements were carried out in $10^{-2} \mathrm{M}$ Tris- $\mathrm{HCl}$ buffer solution at $\mathrm{pH} 7$, as shown in Fig. 3. Before measurement of each sample solution, the tip of the CCD image sensor was rinsed twice with sample solution $(2 \times 150 \mu \mathrm{L})$. After rinsing, the reference electrode (BAS RE-6; $\mathrm{Ag} / \mathrm{AgCl}, 3.3 \mathrm{M}$ potassium chloride solution, porous Vycor) was placed in $150 \mu \mathrm{L}$ of sample solution at a height of $3 \mathrm{~mm}$ above the sensing pixels. The potentials were measured $6 \mathrm{~s}$ after the reference electrode was introduced, to avoid any influence from potassium ion leaking.

\section{Results and Discussion}

\section{Effect of addition of OPMPCOS}

Combination of the plasticized PVC membrane and the CCD $\mathrm{pH}$ sensor was not simple. A CCD potassium ion sensor produced without addition of OPMPCOS gave unstable responses to the potassium ion concentration. The membrane prepared without OPMPCOS initially responded to potassium ion concentration when incorporated in the membrane CCD sensor. However, over several minutes the response to potassium ion concentration gradually disappeared. Eventually, the observed potential was constant at any concentration of potassium ion, indicating that the sensor was insensitive to potassium ion. The concentration response depended on the membrane being dry. As the sensor was conditioned with the 


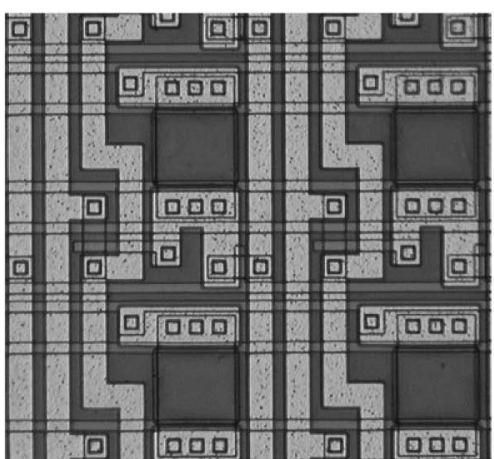

$(\mathrm{A}-1)$

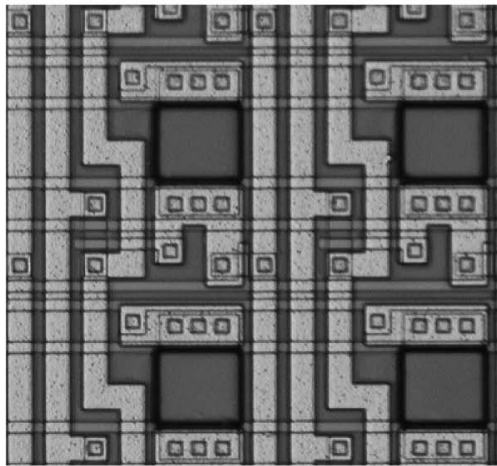

(B-1)

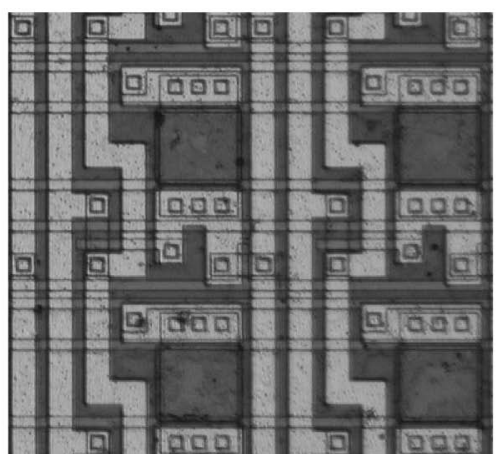

$(\mathrm{A}-2)$

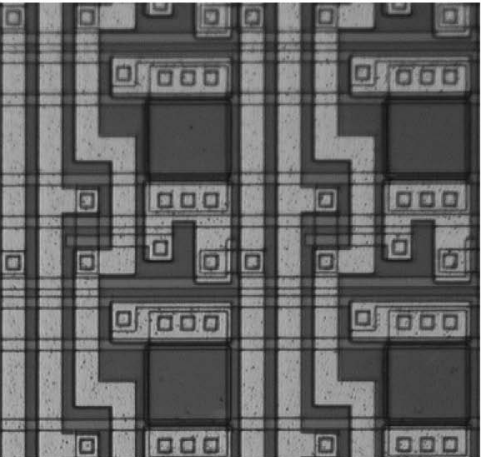

(B-2)

Fig. 4 Snapshots of dry pixels and wet pixels: (A-1) dry without OPMPCOS, (A-2) wet without OPMPCOS, (B-1) dry with OPMPCOS, and (B-2) wet with OPMPCOS.

potassium ion solution, the response disappeared. In order to examine the reason for this unstable response, we observed the plasticized PVC membrane on the sensor using a laser microscope (Figs. 4A-1 and 4A-2). Before the plasticized PVC membrane was soaked in water (Fig. 4A-1), it appeared smooth. However, after $30 \mathrm{~min}$ of soaking in water, the membrane was swollen (Fig. 4A-2). This indicates that water permeated into the interface between the plasticized membrane and the sensor. The plasticized PVC membrane had some ruptures that resulted in poor adhesion to $\mathrm{Si}_{3} \mathrm{~N}_{4}$ of the sensor.

Similar adhesion issues on solid-contacted plasticized PVC membrane electrodes have been reported..$^{25}$ In one case, attempts were made to replace the plasticized PVC membrane with a polysiloxane membrane, ${ }^{26}$ and this improved adhesion. Kolytcheva et al..$^{27}$ applied an intermediate hydrophobic acrylate type polymer layer between the plasticized PVC membrane and a transducer surface. Hosaka et al. ${ }^{28}$ reported that addition of a POSS suppressed the rupture and dewetting of polystyrene thin film. Soong et al..$^{29}$ reported that OPMPCOS could plasticize PVC. Therefore, in this paper, we tried OPMPCOS addition to suppress swelling of the plasticized PVC membrane. Microscope images were obtained of the plasticized PVC membrane containing 15\% OPMPCOS before and after soaking in water (Figs. 4B-1 and 4B-2). Even after $30 \mathrm{~min}$ of soaking in water, the membrane did not swell (Fig. 4B-2). The addition of OPMPCOS also greatly improved the stability of the potential responses. However, a small amount of OPMPCOS was not sufficient to stabilize the sensor response. The 15\% OPMPCOS membrane was intact after $1 \mathrm{~h}$ of conditioning, but longer conditioning degraded the membrane. The membrane sensor with 30\% OPMPCOS maintained stable potentials for a day, and the potential response was stable for a month.

\section{Optimum composition of plasticized PVC membrane}

Bis(benzo-15-crown-5) was used as a neutral-carrier-type ionophore for potassium ion. This ionophore has a high selectivity to potassium ion similar to valinomycin. ${ }^{14}$ Different membrane compositions were prepared by varying the percentages of compounds in the membrane matrix (Table 1). According to the reports on potassium ISE with plasticized PVC, Nernstian response was obtained when using NPOE as the plasticizer. $^{14}$ However, in the presence of OPMPCOS, DOP is more suitable than NPOE. The optimum ratio of DOP to PVC is small in comparison with the plasticized PVC membrane composition for ISE. Because OPMPCOS also works as a plasticizer, a small amount of DOP is sufficient. However, the only OPMPCOS-PVC membrane did not work as the potassium ion sensitive membrane. OPMPCOS is miscible in PVC only up to $15 \% .^{29}$ The membrane containing none of K-TCPB did not produce a satisfactory response. The optimum membrane included $30.0 \%$ OPMPCOS, $44.0 \%$ PVC, $22.0 \%$ DOP, $2.7 \%$ bis(benzo-15-crown-5), and 1.3\% K-TCPB (Table 1). The potential slope of the optimum membrane was $28.8 \mathrm{mV}$ decade $^{-1}$, which is close to the theoretical value of $31.5 \mathrm{mV}$ decade $^{-1}$ mentioned above.

\section{Selectivity of potassium ion membrane}

Figure 5 shows typical calibration curves of a center pixel to potassium ion concentrations. Curve $\mathrm{A}$ indicates the region of the linear calibration is from $10^{-5}$ to $10^{-2} \mathrm{M}$; the lower limit of 
Table 1 Potential response properties of potassium ion CCD sensors with different membrane compositions

\begin{tabular}{|c|c|c|c|c|c|c|}
\hline $\begin{array}{c}\text { OPMPCOS, } \\
\text { wt } \%\end{array}$ & $\begin{array}{l}\text { PVC, } \\
\text { wt } \%\end{array}$ & $\begin{array}{c}\text { Plasticizer, } \\
\text { wt } \%\end{array}$ & $\begin{array}{c}\text { Crown, } \\
\text { wt } \%\end{array}$ & $\begin{array}{c}\text { K-TCPB, } \\
\text { wt } \%\end{array}$ & $\begin{array}{c}\text { Potential } \\
\text { slope/ } \\
\text { mV } \\
\text { decade }^{-1}\end{array}$ & $\begin{array}{c}\text { Dynamic } \\
\text { range, } \\
\log C\end{array}$ \\
\hline 30.0 & 44.0 & $22.0^{\mathrm{a}}$ & 2.0 & 2.0 & 15.7 & $-2--3.5$ \\
\hline 30.0 & 44.0 & $22.0^{\mathrm{a}}$ & 2.7 & 1.3 & 28.8 & $-2--5$ \\
\hline 30.0 & 44.0 & $22.0^{\mathrm{b}}$ & 2.7 & 1.3 & 10.9 & $-2--5$ \\
\hline 30.0 & 44.8 & $22.5^{\mathrm{a}}$ & 2.7 & 0.0 & 9.6 & $-2--3.5$ \\
\hline 30.0 & 33.0 & $33.0^{\mathrm{a}}$ & 2.7 & 1.3 & 13.5 & $-2--5$ \\
\hline 30.0 & 22.0 & $44.0^{\mathrm{a}}$ & 2.7 & 1.3 & 8.5 & $-2--4$ \\
\hline 15.0 & 54.0 & $27.0^{\mathrm{a}}$ & 2.7 & 1.3 & $29.0^{c}$ & $-2--5$ \\
\hline 15.0 & 81.0 & 0.0 & 2.7 & 1.3 & 0 & N.A. \\
\hline 0.0 & 64.0 & $32.0^{\mathrm{a}}$ & 2.7 & 1.3 & $31.3^{\mathrm{d}}$ & $-2--5$ \\
\hline
\end{tabular}

a. The type of plasticizers used was DOP.

b. The type of plasticizers used was NPOE.

c. The first response after 1 -h conditioning.

d. The first response without the conditioning.

Unless particularly mentioned, membranes were conditioned with $10^{-3} \mathrm{M}$ potassium chloride solution for more than $6 \mathrm{~h}$, and the potential slopes were calculated from three measurements.

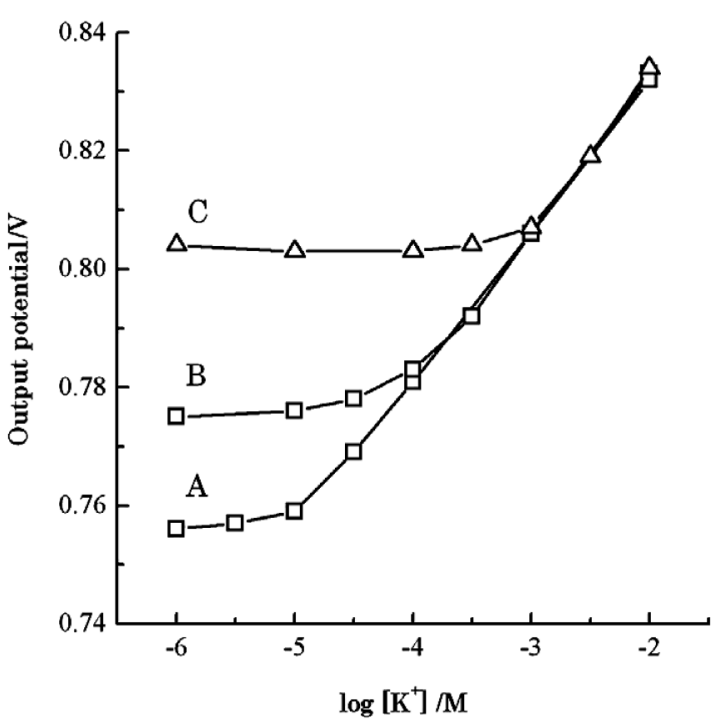

Fig. 5 Calibration curves of potassium ion: A, only potassium ion; $\mathrm{B}$, with $0.01 \mathrm{M}$ sodium ion; $\mathrm{C}$, with $0.01 \mathrm{M}$ rubidium ion.

detection is $5 \times 10^{-5} \mathrm{M}$. According to the mixed solution method $^{30}$ in a $0.01 \mathrm{M}$ interference ion solution (curve B), selectivity coefficients $\left(K_{\mathrm{K}^{+} \mathrm{j}^{\mathrm{n}^{+}}}^{\text {pot }}\right)$ were calculated for alkaline metal ions (Table 2). For lithium, sodium and cesium ions, the selectivity coefficients were less than $1 \%$, but the interference of rubidium ion was larger in the sensor. The values were comparable with the results for an ISE with a bis(benzo-15-crown-5) plasticized PVC membrane. ${ }^{14}$

\section{Deviation of potential response for each pixel}

All pixels did not have uniform potential responses. Potential slopes were obtained for 36 pixels on the $\mathrm{pH}$ and potassium sensors (Tables 3 and 4, respectively). The 36 pixels were systematically chosen from the matrix using the column numbers $5,9,13,17,21$, and 25 and the row numbers $5,9,13$, 17,21 , and 25 . On the $\mathrm{CCD} \mathrm{pH}$ sensor, the mean and standard
Table 2 Selectivity coefficients of the sensor for alkaline metal ions

\begin{tabular}{|c|c|c|c|}
\hline Ion & $K_{\mathrm{K}^{+}, \mathrm{j}^{\mathrm{n}^{+}}}^{\mathrm{pot}}$ & Ion & $K_{\mathrm{K}^{+}, \mathrm{Jn}^{\mathrm{n}+}}^{\mathrm{pot}}$ \\
\hline $\mathrm{Li}^{+}$ & -2.85 & $\mathrm{Rb}^{+}$ & -1.16 \\
\hline $\mathrm{Na}^{+}$ & -2.30 & $\mathrm{Cs}^{+}$ & -2.05 \\
\hline
\end{tabular}

Table 3 Potential slopes $\left(\mathrm{mV} \mathrm{pH}^{-1}\right)$ of 36 individual pixels on the $\mathrm{pH}$ image sensor

\begin{tabular}{lcccccc}
\hline & \multicolumn{6}{c}{ Column } \\
\cline { 2 - 7 } & 5 & 9 & 13 & 17 & 21 & 25 \\
\hline Row 5 & 25 & 26 & 25 & 24 & 25 & 23 \\
Row 9 & 25 & 29 & 30 & 26 & 24 & 22 \\
Row 13 & 32 & 28 & 30 & 29 & 27 & 23 \\
Row 17 & 27 & 25 & 26 & 30 & 26 & 25 \\
Row 21 & 25 & 25 & 25 & 33 & 33 & 26 \\
Row 25 & 32 & 26 & 30 & 33 & 31 & 28 \\
\hline
\end{tabular}

Table 4 Potential slopes $\left(\mathrm{mV} \mathrm{decade}{ }^{-1}\right)$ of 36 individual pixels on the potassium ion sensor

\begin{tabular}{lcccccc}
\hline & \multicolumn{7}{c}{ Column } \\
\cline { 2 - 7 } & 5 & 9 & 13 & 17 & 21 & 25 \\
\hline Row 5 & 27 & 26 & 28 & 29 & 31 & 28 \\
Row 9 & 32 & 27 & 29 & 29 & 34 & 29 \\
Row 13 & 33 & 29 & 29 & 29 & 33 & 21 \\
Row 17 & 30 & 35 & 36 & 29 & 26 & 17 \\
Row 21 & 38 & 37 & 37 & 30 & 24 & 26 \\
Row 25 & 32 & 29 & 28 & 18 & 24 & 18 \\
\hline
\end{tabular}

deviation of the 36 potential slopes were 27.2 and $3.1 \mathrm{mV} \mathrm{pH}^{-1}$ (Table 3). On the CCD potassium ion sensor, the mean and standard deviation of the 36 potential slopes were 28.8 and $5.1 \mathrm{mV}$ decade $^{-1}$ (Table 4). The standard deviation for the CCD potassium ion sensor was slightly larger than that of the $\mathrm{pH}$ sensor.

\section{Monitoring dynamic real-time images}

As discussed above, each pixel produced a different potassium ion potential response. To monitor dynamic real-time images, the pixels required calibration before operation of the image sensor. Calibration was performed with three solutions of $10^{-2}$, $10^{-3}$ and $10^{-4} \mathrm{M}$ potassium ions. Unfortunately, some pixels could not be calibrated. Real-time images of potassium ion concentration were obtained when monitoring leaking of $\mathrm{KCl}$ solution from a $3.3 \mathrm{M} \mathrm{KCl}$ solution $\mathrm{Ag} / \mathrm{AgCl}$ electrode for $120 \mathrm{~s}$ (Fig. 6). During leakage, the potassium ion concentration spread out in a circular manner. The CCD ion image sensor acquired images every $0.2 \mathrm{~s}$, although figures are displayed for only 10 of the more than 600 images obtained. The whole time to obtain an image on LAPS was more than a half minute ${ }^{8}$ such images were only still pictures. In the CCD ion image sensor, the number of short-time images obtained effectively allowed production of a movie for the leakage of $\mathrm{KCl}$. 


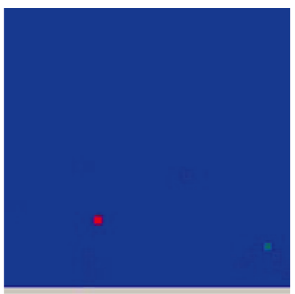

$\mathbf{0} \mathbf{s}$

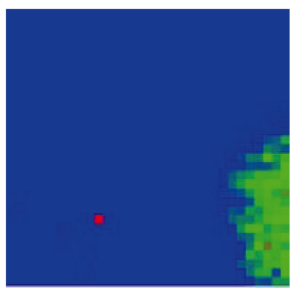

$20 \mathrm{~s}$

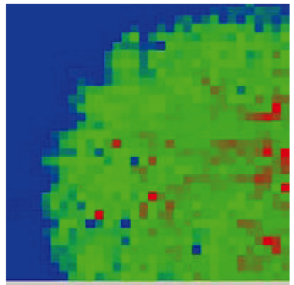

$90 \mathrm{~s}$

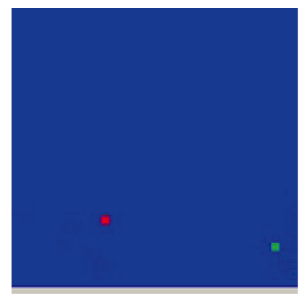

$5 \mathbf{s}$

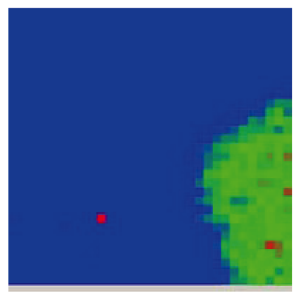

$30 \mathrm{~s}$

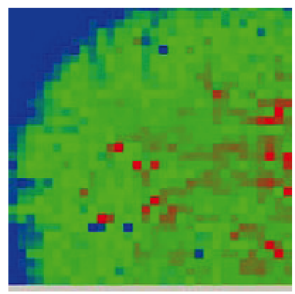

$120 \mathrm{~s}$

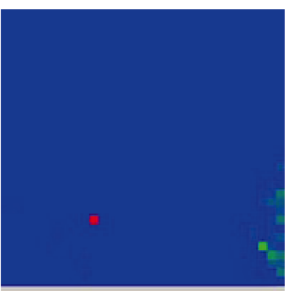

$10 \mathrm{~s}$

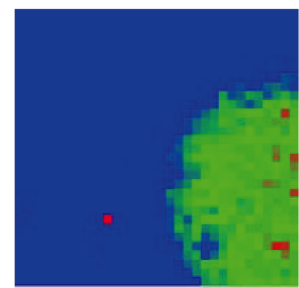

$40 \mathrm{~s}$

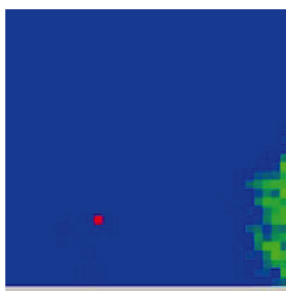

$15 s$

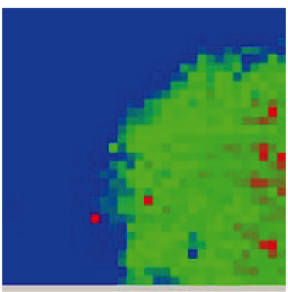

$60 \mathrm{~s}$

Fig. 6 Real-time images of potassium ion concentration during monitoring of $\mathrm{KCl}$ solution leakage from a $3.3 \mathrm{M} \mathrm{KCl} \mathrm{Ag/AgCl} \mathrm{electrode.}$

\section{Conclusions}

We developed a potassium ion imaging sensor using a two-dimensional sensing membrane matrix of fixed sensing pixels with MOS circuit processes, CCD technology, and an ion selective membrane. The addition of a POSS as a stabilizer of the sensing PVC membrane was useful to improve its adhesion. The CCD potassium ion image sensor was successfully applied to monitor leaching of potassium ion from a $3.3 \mathrm{M} \mathrm{KCl} \mathrm{Ag/AgCl}$ reference electrode. The success of this image sensor could facilitate a wide range of applications for sensors prepared by similar methods with different plasticized PVC membranes. However, the resolution of the present sensor was on a sub-micro-order, and as such insufficient to measure ions in cellular biology. Therefore, the resolution requires improvement. Although a fluorescence microscope already possesses a high resolution and a very fast response, label-free ion imaging by the present method is very useful. In comparison with LAPS at presence, this CCD ion image sensor is superior in possessing a high-speed imaging, portability, and easy handling.

\section{References}

1. M. Navratil, G. A. Mabbott, and E. A. Arriage, Anal. Chem., 2006, 78, 4005.

2. D. Hafeman, J. Parce, and H. McConnell, Science, 1988, 240,1182

3. T. Wagner, R. Molina, T. Yoshinobu, J. P. Kloock, M.
Biselli, M. Canzoneri, T. Schnitzler, and M. J. Schöning, Electrochim. Acta, 2007, 53, 305.

4. M. J. Milgrew, M. O. Riehle, and D. R. S. Cumming, Sens. Actuators, B, 2005, $111-112,347$.

5. K. Sawada, S. Mimura, K. Tomita, T. Nakanishi, H. Tanabe, M. Ishida, and T. Ando, IEEE T. Electron Dev., 1999, 46, 1846.

6. T. Hizawa, K. Sawada, H. Takao, and M. Ishida, Sens. Actuators, B, 2006, 117, 509.

7. T. Hizawa, J. Matsuo, T. Ishida, H. Takao, H. Abe, K. Sawada, and M. Ishida, IEEE Transducers \& Eurosensors '07, 2007, 1311.

8. M. Nomura, T. Nakao, T. Nakanishi, S. Takamatsu, and K. Tomita, Anal. Chem., 1997, 68, 977.

9. Y. Maruyama, S. Terao, and K. Sawada, Biosens. Bioelectron., 2009, 24, 3108.

10. E. Eya and G. A. Rechnitz, Anal. Chem., 1971, 43, 370.

11. O. Ryba and J. Petránek, J. Electroanal. Chem., 1973, 44, 425.

12. R. W. Cattrall, S. Tribuzio, and H. Freiser, Anal. Chem., 1974, 46, 2223.

13. M. Semler and H. Adametzová, J. Electroanal. Chem., 1974, 56, 155.

14. K. Kimura, T. Maeda, H. Tamura, and T. Shono, J. Electroanal. Chem., 1979, 95, 91.

15. M. Yamauchi, A. Jyo, and N. Ishibashi, Anal. Chim. Acta, 1982, 136, 399.

16. E. Lindner, K. Tóth, M. Horváth, E. Pungor, B. Ágai, I. Bitter, L. Tökeand, and Z. Hell, Fresenius' J. Anal. Chem., 1985, 322, 157. 
17. M. Dror, E. A. Bergs, and R. K. Rhodes, Sens. Actuators, 1987, 11, 23

18. A. S. Attyae, G. D. Christian, R. Y. X. Wen, and R. A. Bartsch, Electroanalysis, 1992, 4, 51.

19. D. Lee and J. D. R. Thomas, Talanta, 1994, 41, 901.

20. A. Bratov, N. Abramova, J. Munoz, C. Dominigguez, S. Alegret, and J. Bartroli, Anal. Chem., 1995, 67, 3589.

21. P. C. Hauser, D. W. L. Chiang, and G. A. Wright, Anal. Chim. Acta, 1995, 302, 241.

22. K.-C. Oh, E. C. Kang, Y. L. Cho, K.-S. Jeong, E.-A. Yoo, and K.-J. Paeng, Anal. Sci., 1998, 4, 1009.

23. S. Kim, H. Kim, K. H. Noh, S. H. Lee, S. K. Kim, and J. S. Kim, Talanta, 2003, 61, 709.

24. T. Katsu, Y. Yokoyama, K. Ueda, K. Kohno, and T. Yamato,
Anal. Sci., 2005, 21, 175.

25. M. Fibbioli, W. E. Morf, M. Badertscher, N. F. de Rooij, and E. Pretsch, Electroanalysis, 2000, 12, 1286.

26. D. N. Reinhoudt, J. F. J. Engbersen, Z. Brzózka, H. H. van den Vlekkert, G. W. N. Honig, H. A. J. Holterman, and U. H. Verkerk, Anal. Chem., 1994, 66, 3618.

27. N. V. Kolytcheva, O. M. Petrukhin, N. V. Filipieva, and H. Müller, Sens. Actuators, B, 1998, 48, 491.

28. N. Hosaka, K. Tanaka, H. Otsuka, and A. Takahara, Compos. Interface, 2004, 11, 297.

29. S. Y. Soong, R. E. Cohen, and M. C. Boyce, Polymer, 2007, $48,1410$.

30. E. Pungor, K. Toth, and H. Pall, Pure Appl. Chem., 1977, $51,1913$. 